\title{
Analysis of obstetric complications and uterine connective tissue in tenascin-X-deficient humans and mice
}

\author{
David F. Egging • Ivonne van Vlijmen-Willems • \\ Jiwon Choi - Anita C. T. M. Peeters • Desiree van Rens • \\ Guido Veit • Manuel Koch • Elaine C. Davis • \\ Joost Schalkwijk
}

Received: 19 August 2007 / Accepted: 22 January 2008 / Published online: 12 March 2008

(C) The Author(s) 2008

\begin{abstract}
Tenascin-X (TNX) is a large, multi-domain, extracellular matrix glycoprotein. Complete deficiency of TNX in humans leads to a recessive form of Ehlers-Danlos syndrome (EDS), and TNX haploinsufficiency is a cause of hypermobility type EDS. EDS patients appear to have a higher risk of several complications during pregnancy, such as pelvic instability, premature rupture of membranes, and postpartum hemorrhage. Here, we present a study of
\end{abstract}

This work was supported by grants from the Dutch Program Tissue Engineering (DPTE) and the Canadian Institutes of Health Research (CIHR). E.C.D. is a Canada Research Chair.

\footnotetext{
D. F. Egging · I. van Vlijmen-Willems ·

D. van Rens $\cdot$ J. Schalkwijk

Department of Dermatology,

Nijmegen Centre for Molecular Life Sciences,

Radboud University Nijmegen Medical Centre,

Nijmegen, The Netherlands

J. Choi $\cdot$ E. C. Davis

Department of Anatomy \& Cell Biology, McGill University,

Montreal, QC, Canada
}

\section{A. C. T. M. Peeters}

Department of Endocrinology,

Radboud University Nijmegen Medical Centre,

Nijmegen, The Netherlands

G. Veit $\cdot$ M. Koch

Center for Biochemistry, Medical Faculty,

University of Cologne,

Cologne, Germany

\section{Koch}

Department of Dermatology and Center for Molecular Medicine

Cologne, Medical Faculty, University of Cologne,

Cologne, Germany

J. Schalkwijk $(\bowtie)$

P.O. Box 9101, 6500 HB Nijmegen, The Netherlands

e-mail: j.schalkwijk@derma.umcn.nl genitourinary and obstetric complications in TNX-deficient women of reproductive age. We have found complications, such as uterus prolapses, that are in agreement with previous findings in other EDS types. In TNX knockout (KO) mice, we have observed mild pregnancy-related abnormalities. Morphological and immunohistological analysis of uterine tissues has not revealed obvious quantitative or spatial differences between TNX KO and wildtype mice with respect to collagen types I, III, V, and XII or elastic fibers. We conclude that TNX-deficient women are at risk of obstetric complications, but that TNX KO mice show only a mild phenotype. Furthermore, we show that TNX is involved in the stability of elastic fibers rather than in their initial deposition.

Keywords Ehlers-Danlos syndrome - Tenascin-X .

Collagen · Elastin · Pregnancy · Human ·

Mouse (TNX knockout; C57BL/6)

\section{Introduction}

Tenascin-X (TNX) is a large, multi-domain, extracellular matrix (ECM) glycoprotein composed of epidermal growth factor (EGF) like-repeats, fibronectin type III repeats, and a C-terminal fibrinogen domain (Bristow et al. 1993; Lethias et al. 1996; Elefteriou et al. 1997; Ikuta et al. 1998; Tucker et al. 2006). Complete deficiency of TNX in humans leads to a rare recessive form of Ehlers-Danlos Syndrome (EDS), and TNX haploinsufficiency is a cause of hypermobility type EDS. Patients of both EDS types exhibit mild to severe joint hypermobility. The skin of TNX-deficient patients is markedly lax with poor recoil properties and shows easy bruising. The collagen density appears reduced in the dermis of these patients, and the elastic fibers are 
abnormal (Burch et al. 1997; Schalkwijk et al. 2001; Zweers et al. 2003; Peeters et al. 2004; Lindor and Bristow 2005). Most of the literature concerning pregnancy in EDS uses the old classification of nine subgroups. In our study, we use the revised classification of six subtypes of EDS (Beighton et al. 1998). Tissue fragility is a hallmark of EDS and is present in all the different subtypes. EDS patients appear to have a higher risk of several complications during pregnancy, such as pelvic instability, premature rupture of membranes, and postpartum hemorrhage. Pregnancy in classical and hypermobility type EDS has a relative favorable maternal and neonatal outcome. Pregnancy in vascular type EDS patients is associated with severe complications including maternal mortality (Pepin et al. 2000; Carley and Schaffer 2000; Roop and Brost 1999; Wegrowski et al. 1999; Ramos-e-Silva et al. 2006; Lind and Wallenburg 2002; Kuczkowski 2005; Parry and Strauss 1998). The effect of TNX deficiency on pregnancy has not been studied so far, and only one case report of pregnancy in a TNX-deficient woman has been reported in the literature (Lindor and Bristow 2005). Here, we present a study of all known pregnancies and genito-urinary (GU) abnormalities in TNX-deficient woman of reproductive age identified in our clinic (Schalkwijk et al. 2001) and in the literature (Lindor and Bristow 2005; Schalkwijk et al. 2001). Furthermore, we have extended our studies to a TNX knockout (KO) mouse model in which we have investigated uterine development during pregnancy. We have previously established that TNX is essential for the development of tissue strength in the skin and is able to bind to elastin, a major component of elastic fibers, and to collagens type I, III, V, and XII (Egging et al. 2006a, b; Veit et al. 2006). We have investigated the expression of these molecules at the protein level.

\section{Materials and methods}

\section{TNX-deficient patients}

We investigated pregnancies and GU abnormalities in all currently identified female tenascin-X deficient patients of reproductive age identified in our clinic and in the literature. The study protocol was approved by the local medical ethics committee, and written informed consent was obtained from the patients.

\section{Experimental animals}

TNX knockout (KO) mice were obtained as described previously (Mao et al. 2002). For all studies, we used TNX $\mathrm{KO}$ mice that were crossed back with six generations of C57BL/6N mice. Wildtype C57BL/6 (WT) mice were used as a control. All mice investigated for pregnancy abnormalities and morphological changes in uterus tissue were between 2 and 6 months of age, reflecting a normal age distribution of a breeding mice population. Skin samples were taken from 2-month-old and 9-month-old mice, and aortic tissue was obtained from 9-month-old mice. The experimental design was approved by the Animal Use Committee of Radboud University, Nijmegen.

\section{Breeding}

Breeding pairs were kept in a 5:1 female:male ratio. Females were inspected daily for vaginal plugs, and those with plugs were isolated and inspected each day for abnormalities and progression of pregnancy. Litter size was determined after birth. Neonatal survival is defined as the difference in litter size after partus and 2 weeks postpartum.

Processing of samples for (immuno)histochemistry

Mice were killed in a sealed compartment by exposure to a mixture of carbogen gas and increasing concentrations of $\mathrm{CO}_{2}$. Skin samples for frozen sections were embedded in Tissue-Tek O.C.T. compound (Sakura Finetek Europe, The Netherlands) and snap frozen in liquid nitrogen. Skin samples for paraffin sections were fixed in $4 \%$ buffered formalin for $4 \mathrm{~h}$.

Affinity-purified TNX antibody production

TNX FNIII repeats 27-32 were amplified by polymerase chain reaction (PCR; forward primer: 5'-GGAATTCGAGC TACCTCCCCAC-3', reverse primer: 5'-CAGGTCGACT CAGGTGAAAGAGGTGGA-3') by using a previously described 2.7-kb human TNX cDNA as a template (Morel et al. 1989). The PCR product was ligated into the pCR2.1TOPO vector (Invitrogen, Breda, The Netherlands) according to the manufacturer's instructions for easy digestion with restriction enzymes. The pCR2.1 TOPO vector with insert was digested with EcoRI and SalI. The region coding for FNIII27-32 was inserted into the EcoRI/ SalI site of the pET28(a)+ plasmid (Brunschwig Chemie, Amsterdam, The Netherlands). The sequence of the TNX domains was verified by dideoxy sequencing with a 3730 DNA analyzer (Applied Biosystems, Nieuwekerk a/d IJssel, The Netherlands). TNX FNIII27-32 protein was expressed and purified according to the manufacturer's instructions (Brunschwig Chemie). Purified TNX FNIII27-32 protein was used for immunization of a rabbit. Aliquots of $500 \mu \mathrm{g}$ TNX FNIII27-32 in $500 \mu$ l phosphate-buffered saline were mixed with an equal volume of Freund's complete adjuvant for the first injection and Freund's incomplete adjuvant for boosters. Three injections were administered subcutaneously 
Table 1 Pregnancy in TNX-deficient woman (VUE vaginal uterine extirpation, IUD intra-uterine death, CAH congenital adrenal hyperplasia). Age represents the age of the patient at the anamnesis

\begin{tabular}{|c|c|c|c|c|}
\hline Patient ID & $\begin{array}{l}\text { Age } \\
\text { (years) }\end{array}$ & $\begin{array}{l}\text { Gravida number/ } \\
\text { Para number }\end{array}$ & Genito-urinary complications & Specification \\
\hline 1 & 50 & G1P1 & None & None \\
\hline $\begin{array}{l}2 \text { (sister of } \\
\text { patient } 1)\end{array}$ & 60 & $\mathrm{G} 2 \mathrm{P} 2$ & $\begin{array}{l}\text { VUE after uterine prolapse (at age } 49 \text { ) } \\
\text { Vaginal prolapse } 2 \text { weeks after VUE }\end{array}$ & $\begin{array}{l}\text { None } \\
\text { None }\end{array}$ \\
\hline 3 & 46 & G0P0 & None & $\begin{array}{l}\text { Was born prematurely (week } 35 \text { ) with } \\
\text { shoulder luxation, rectal prolapse at age } 1\end{array}$ \\
\hline $\begin{array}{l}4 \text { (sister of } \\
\text { patient } 3)\end{array}$ & 51 & G3P3 & $\begin{array}{l}\text { One incident of hemorrhage postpartum } \\
(>1000 \mathrm{ml} \text { blood loss })\end{array}$ & None \\
\hline 5 & 38 & G0P0 & None & $\mathrm{CAH}$ \\
\hline 6 & 51 & G3P2 & $\begin{array}{l}\text { IUD ( } 24 \text { weeks) with relatively large } \\
\text { blood loss } \\
\text { Undefined prolapse (at age } 36 \text { ) }\end{array}$ & $\begin{array}{l}\text { Deceased at age 51, severe co-morbidity } \\
\text { including cardiomyopathy, arrhythmia, } \\
\text { arteriosclerosis, and amputation of left leg } \\
\text { (Schalkwijk et al. 2001). }\end{array}$ \\
\hline 7 & $57^{*}$ & G4P4 & $\begin{array}{l}\text { Precipitious second stage at term for all births } \\
\text { Uterine prolapse (at age 20), also recurrent } \\
\text { rectal prolapses }\end{array}$ & Lindor and Bristow 2005 \\
\hline
\end{tabular}

at 3-week intervals. Polyclonal antibodies against TNX FNIII27-32 were purified by affinity chromatography on a column with the antigen coupled to $\mathrm{CNBr}$-activated sepharose 4B (GE Healthcare Life Sciences, Diegem, Belgium).

Histopathology, histochemistry, and immunohistochemistry

Staining of elastic fibers was performed by modified Hart's stain on paraffin sections (7 $\mu \mathrm{m}$; Starcher et al. 2005). Paraffin sections were also stained with hematoxylin and eosin (H\&E) stain to assess uterus morphology and pathology, in collaboration with a professional pathologist. Frozen sections $(7 \mu \mathrm{m})$ were stained with antibodies against collagen types I, III, and V (SouthernBiotech, USA) and elastin (Elastin Products, USA) as previously described by Egging et al. (2006b). Collagen XII was stained as previously described by Veit et al. (2006). TNX was stained with affinity-purified antibodies directed against FNIII27-32 of TNX. Detection was performed with antibodies labeled with fluorescein isothiocyanate (FITC, green; DakoCytomation, Denmark) and Alexa Fluor 594 (AF594, red; Molecular Probes, The Netherlands). Cell nuclei were made visible with 4,6-diamidino-2-phenylindole (DAPI, blue; Molecular Probes) counterstaining. Assesment of immunostaining was performed as previously described (Egging et al. 2007, 2006b). Images were captured and processed with Axiovision software (Carl Zeiss, The Netherlands).

\section{Electron microscopy}

For electron microscopy, WT and TNX KO samples from uterine wall at 3 weeks post-partum, skin from 2-month-old and 9-month-old mice, and aortas from 9-month-old mice were fixed in $3 \%$ glutaraldehyde in $0.1 \mathrm{M}$ sodium cacodylate overnight and washed in $0.1 \mathrm{M}$ sodium cacodylate buffer. The tissues were then sequentially treated with osmium tetroxide, tannic acid, and uranyl acetate and then dehydrated and embedded in Epon as previously described (Davis 1993). Thin sections $(60 \mathrm{~nm})$ were counterstained with $7 \%$ uranyl acetate in absolute methanol and lead citrate and examined in a Tecnai 12 transmission electron microscope, at $120 \mathrm{kV}$.

\section{Statistics}

For statistical analyses, Fisher's exact or Chi-square tests were used where appropriate for proportional data. Student's t-test was used to compare mean litter size after partus and neonatal survival (difference in litter size after partus and 2 weeks postpartum). A $P$-value of $<0.05$ was considered statistically significant.

Table 2 Pregnancy in TNX-deficient mice

\begin{tabular}{lll}
\hline Genito-urinary complications & $\begin{array}{l}\text { TNX KO mice } \\
\text { Number of mice }\end{array}$ & $\begin{array}{l}\text { WT mice } \\
\text { Number of mice }\end{array}$ \\
\hline $\begin{array}{l}\text { Maternal death during } \\
\text { pregnancy }\end{array}$ & 1 & 0 \\
$\begin{array}{l}\text { Miscarriage } \\
\text { Obstruction during partus }\end{array}$ & 1 & 0 \\
$\begin{array}{l}\text { Excessive bleeding of vagina } \\
\text { (as seen at vaginal plug }\end{array}$ & 2 & 3 \\
check) & 0 \\
Cannibalism after partus & 1 & \\
Total number of evaluated & 36 & 1 \\
pregnancies & & 31 \\
\hline
\end{tabular}




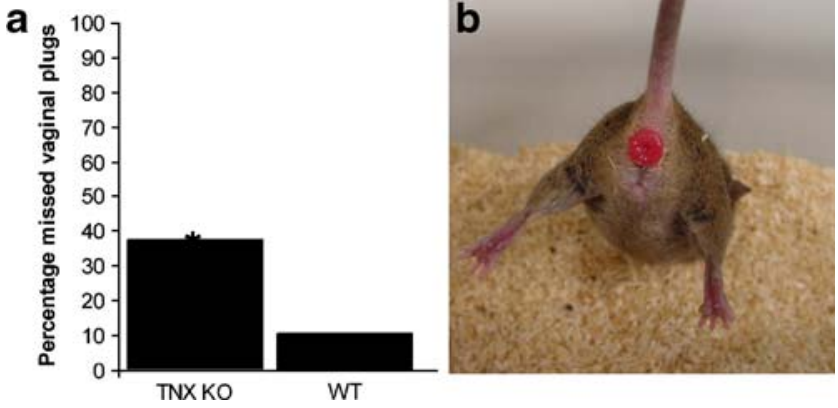

Fig. 1 TNX KO mice abnormalities. Vaginal plugs, which are present after mating, are much more difficult to asses in TNX KO mice than in WT mice. This resulted in a significant increase of pregnancies in which the date of impregnation was unknown (a, ${ }^{*} P<0.025$, Chisquare test). Total evaluations: TNX KO mice, $n=32$; WT mice, $n=28$. In this study, no uterine prolapses were observed, although some TNX KO mice suffered from a rectal prolapse (b). Rectal prolapses were also observed in TNX-deficient patients, although the incidence in TNX KO mouse was lower $(<1 \%$ in mice $)$

\section{Results}

Pregnancy in TNX-deficient patients

We investigated pregnancy and GU abnormalities in TNXdeficient woman of reproductive age. General reproduction characteristics and GU abnormalities of female TNXdeficient patients are presented in Table 1. Maternal and neonatal outcome was generally normal; one out of 13 pregnancies resulted in an intrauterine death of the fetus. Tissue laxity of TNX-deficient patients was demonstrated by the occurrence of vaginal, uterine, and rectal prolapses, even at a relative young age. One case of postpartum hemorrhage was observed in 12 childbirths. None of our patients had urinary incontinence symptoms. TNX-deficient EDS is an autosomal recessive disorder; therefore, all offspring of a TNX-deficient patient and an unaffected individual are obligatory heterozygotes. We have previously found that approximately $60 \%$ of adult females that are haploinsufficient for TNX suffer from hypermobility type EDS or benign joint hypermobility syndrome (Zweers et al. 2003). We found no obvious abnormalities (e.g. floppy infant syndrome, premature birth) in the neonates (obligatory heterozygotes) of our TNX-deficient population; however, some TNX-deficient patients themselves were born prematurely (Table 1; Lindor and Bristow 2005). Four out of six of the TNX-deficient women had postpartum complications (one of the patients had no pregnancies). This was in agreement with the findings in the literature of an increase in maternal GU complications in EDS-deficient women compared with the control population (Ainsworth and Aulicino 1993; Carley and Schaffer 2000; Kuczkowski 2005; Lind and Wallenburg 2002; Ramos-e-Silva et al. 2006).
Pregnancy in TNX KO mice

We investigated GU and pregnancy-related abnormalities in TNX KO and WT mice ranging between 2-6 months of age. Litter size (TNX KO: $7 \pm 2$ pups, WT: $7 \pm 3$ pups) and neonatal survival (TNX KO: $74 \% \pm 36 \%$, WT: $54 \% \pm 40 \%$ ) did not differ significantly (Student's $t$-test). GU abnormalities of the TNX KO and WT mice are presented in Table 2. Overall, we noted relatively few pregnancy-related abnormalities. Obstruction of the uterine or vaginal canals during partus resulting in a failure to deliver pups was noted more often in WT mice compared with TNX KO mice, but the difference was not significant (Chi-square test). The length of term did not differ significantly for the TNX KO mice (mean: 19.3 days) compared with WT mice (mean: 19.6 days, Fisher's exact test). A striking difference, however, between TNX KO and WT was found for the location of the vaginal plug that was present after mating. Generally, the vaginal plug in TNX KO mice was located much deeper in the vaginal canal than in WT mice. This made identification of vaginal plugs in TNX KO mice markedly more difficult, resulting in a significant increase in pregnancies with unknown length of pregnancy (Fig. 1a, Chi-square test). No uterine or rectal prolapses were observed in this particular study (67 pregnancies of $\mathrm{KO}$ and WT mice). We did, however, observe rectal prolapses in the breeding colony of our TNX KO mice population (shown in Fig. 1b), albeit at a low frequency $(<1 \%)$. We did not observe rectal prolapses in our WT mice population.

\section{Structure of mouse uterus}

The mouse uterus consists of three layers: an outer layer, which includes the single-cell layered perimetrium and a thin layer of connective tissue; a muscular layer, the myometrium, composed of two oppositely orientated layers of muscle; and an endometrium, which undergoes remodeling during the menstrual cycle and pregnancy. The

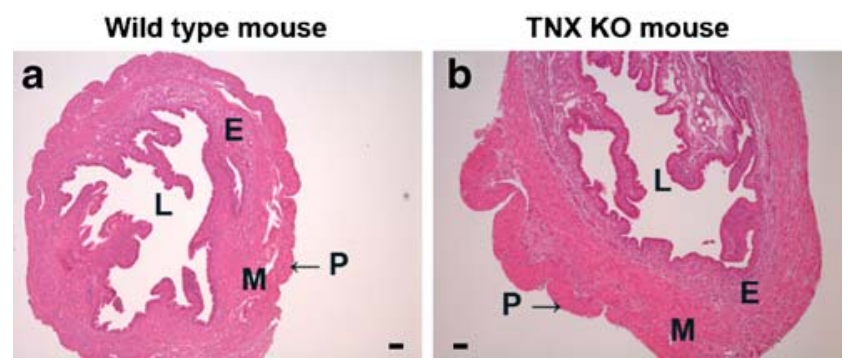

Fig. 2 Structure of TNX KO and WT uterus. H\&E-stained sections of the uterus of WT mice (a) and of TNX KO mice (b). No differences in the structure of the uteri were noticeable between TNX KO and WT mice. The mouse uterus consists of a thin outer layer, the perimetrium $(P)$. A muscle layer, the myometrium $(M)$, consists of two oppositely orientated layers of muscle, although this is difficult to distinguish in H\&E-stained slides ( $E$ endometrium, $L$ lumen). Bars $0.01 \mathrm{~mm}$ 
endometrium contains luminal and glandular epithelial cells, stromal cells, resident immune cells of various types, and endothelial cells. No differences in the overall morphology of the uterine tissues were noticeable between TNX KO and WT mice (Fig. 2; uteri on 1 day postpartum) as assessed by light microscopy of H\&E-stained sections. As we mainly focused on the ECM compartment of the uterus, we did not attempt to make quantitative analyses of the cell type distribution.

\section{TNX distribution in mouse uterus}

TNX was present throughout the uterus of virgin mice and in the uterus during and after pregnancy (Fig. 3a-c). Immunostaining for TNX was discontinuous in the perimetrium (Fig. 3a-c,f). TNX was detected in the endometrium, although the epithelium lining the endometrium was negative for TNX (Fig. 3d). Furthermore, TNX was present in the layers of connective tissue ensheathing the muscle bundles of the myometrium (Fig. 3f). Overall, no change in the localization of TNX immunostaining was observed during and after pregnancy. The specificity of our TNX antibody was demonstrated by the complete absence of positive staining in the tissues of the TNX KO mice (Fig. 3e,g).

\section{Collagen distribution in mouse uterus}

We have previously demonstrated the binding and the colocalization of TNX with collagen types I, II and V, in the skin (Egging et al. 2006a, b). In the uterus, TNX also colocalizes with major fibrillar collagens types I, III, and V, as is shown for uteri 3 weeks postpartum (Fig. 4). The collagens are present in the perimetrium, the endometrium, and the layers of the connective tissue ensheathing the muscle bundles of the myometrium. Similar results have been obtained for uteri from virgin, 13-days pregnant, and 1-day postpartum mice. No differences in collagen type I, III, and V immunostaining are found between WT and TNX KO mice (data not shown), which is in agreement with our
Fig. 3 Immunostaining of TNX in the uterus ( $P$ perimetrium, $M$ myometrium showing longitudinal muscle bundles, $M^{*}$ myometrium showing transverse muscle bundles, $E$ endometrium, Epi epithelium of the lumen, $L$ lumen). TNX (green) is present throughout the uterus of virgin mice (a) and in the uterus during and after pregnancy, shown for uteri at 13 days pregnant (b) and 3 weeks postpartum (c). Cell nuclei are stained with DAPI (blue). TNX is present in the endometrium (d) and the layers of connective tissue ensheathing muscle bundles of the myometrium (f). TNX immunostaining of the perimetrium is relatively weak (a-c, f). The epithelium of the lumen is negative for TNX (d). The specificity of the TNX antibody is demonstrated in $\mathbf{e}, \mathbf{g}$. d-g Uteri at 3 weeks postpartum. Bars $50 \mu \mathrm{m}$

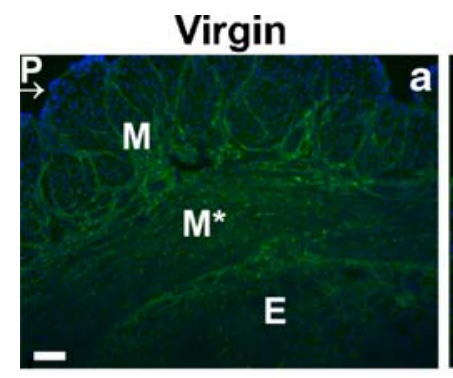

\section{3 days pregnant}

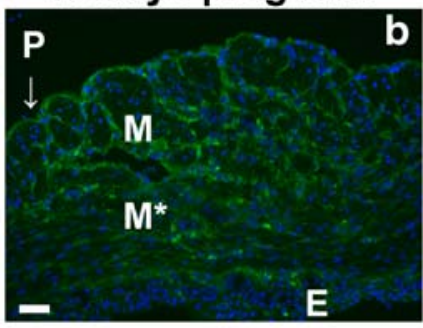

3 weeks post partum

Wild type mouse
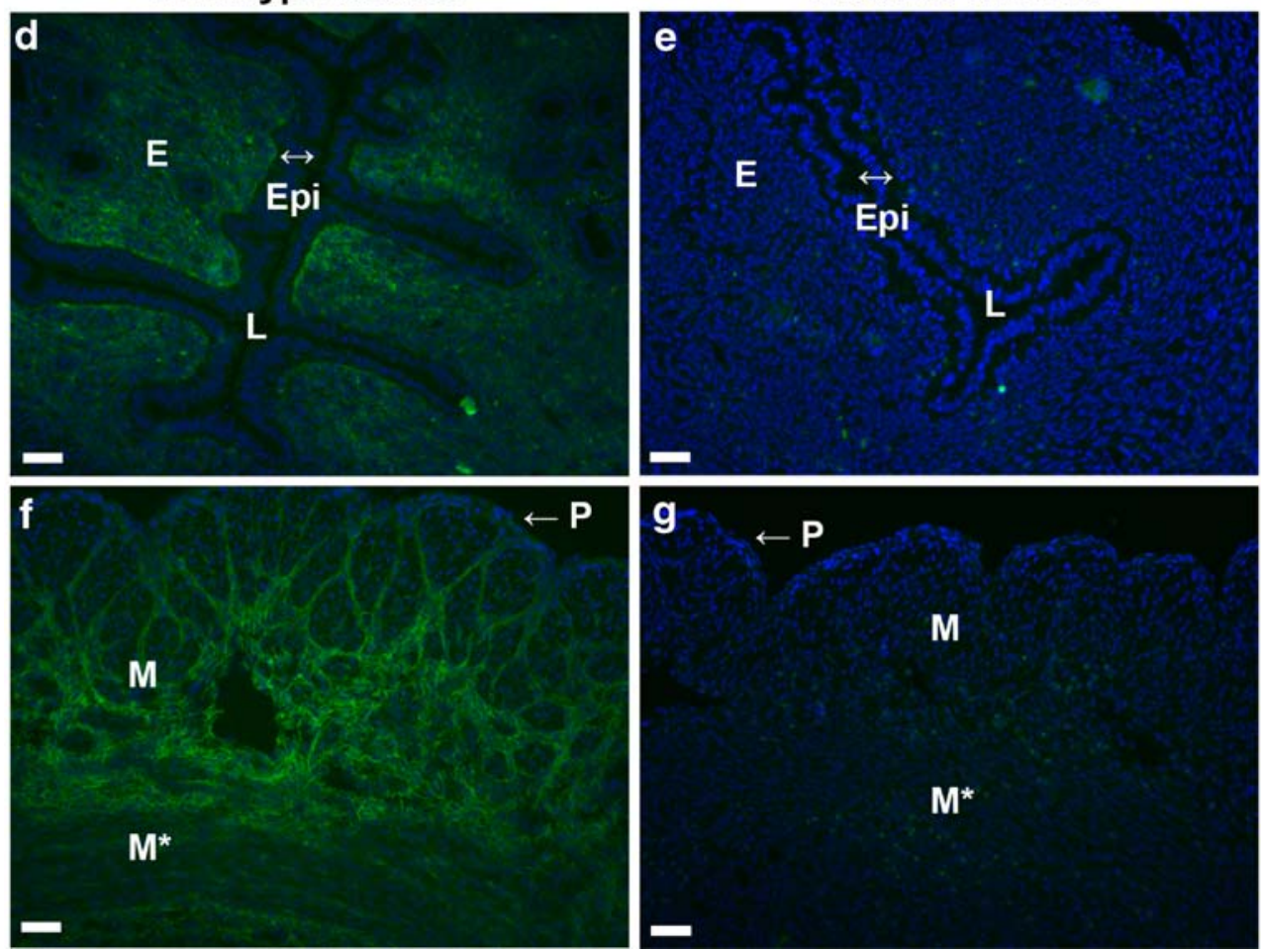


\section{collagen}
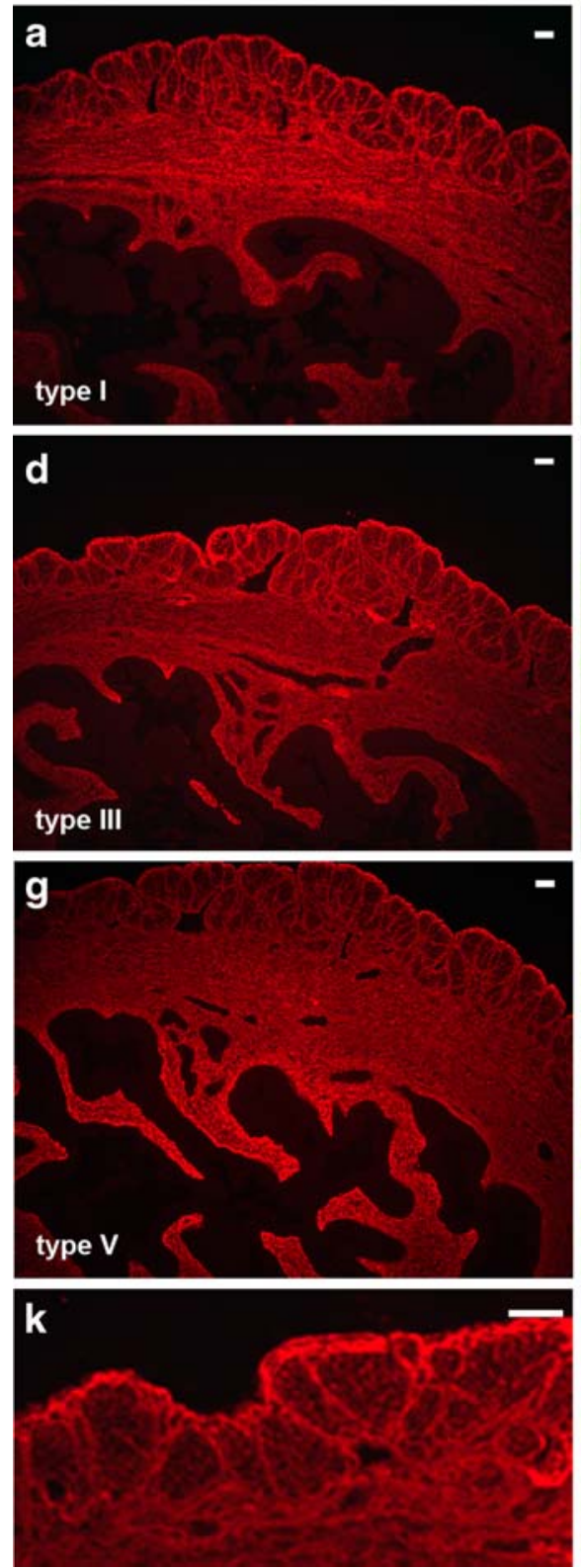

Fig. 4 TNX colocalizes with major fibrillar collagens types I, III, and $\mathrm{V}$ ( $P$ perimetrium, $M$ myometrium with longitudinal muscle bundles, $M^{*}$ myometrium with transverse muscle bundles, $E$ endometrium, Epi epithelium of the lumen, $L$ lumen). TNX (b, e, h, green) and collagen types I (a), III (d), and V (g, red) colocalize (c, f, i, yellow, orange, magenta) in uteri 3 weeks postpartum. Similar results have been

observations in skin (Egging et al. 2006b). TNX does not exclusively colocalize with collagens, however, because TNX also cololalizes with other ECM components such as (tropo)elastin. Collagen type XII, an interaction partner of TNX (Veit et al. 2006), is present throughout the uterus (Fig. 5). Collagen type XII occurs in the transverse muscle bundles of the myometrium around blood vessels and around the lumen, although the signal intensity is not completely continuous around the lumen and blood vessels. merge + DAPI cell staining

-

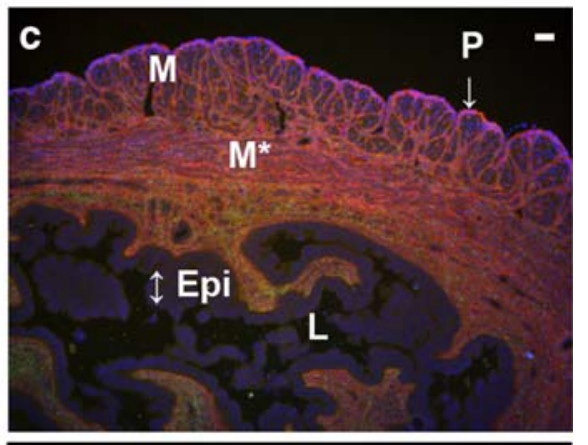

$-$

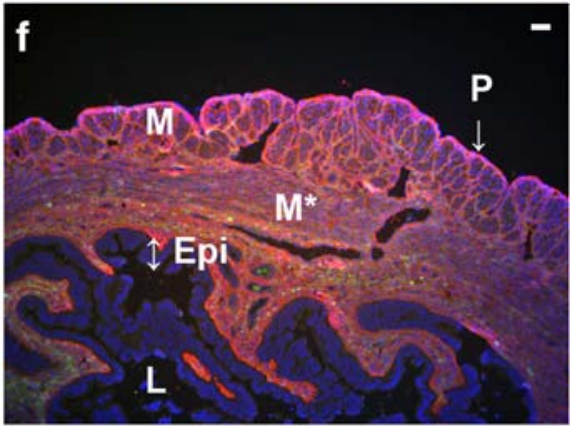

$-$

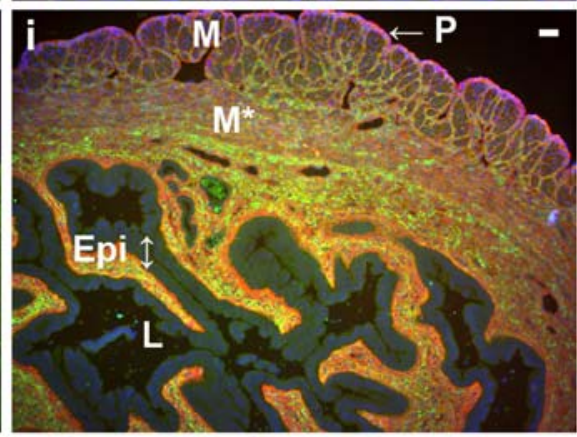

m

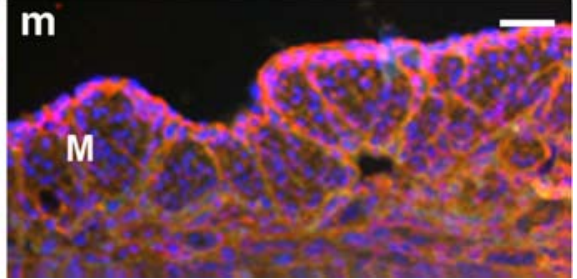

obtained for uteri from virgin, 13-days pregnant, and 1-day postpartum mice. No differences in collagen type I, III, and V immunostaining are apparent between WT and TNX KO mice (data not shown). In $\mathbf{k}, \mathbf{l}, \mathbf{m}$, higher magnification images of the myometrium are shown to demonstrate the colocalization of the fibrillar collagens with TNX (collagen type III is used as an example). Bars $50 \mu \mathrm{m}$

TNX and collagen type XII are both present throughout the uterus. No differences in the collagen type XII localization in the uterus between WT (Fig. 5a,c,e,g) and TNX KO (Fig. 5b,d,f,h) mice have been observed.

Elastic fibers in mouse tissues

Elastic fibers in the skin of TNX-deficient patients are known to be abnormally shaped (Zweers et al. 2004), and 

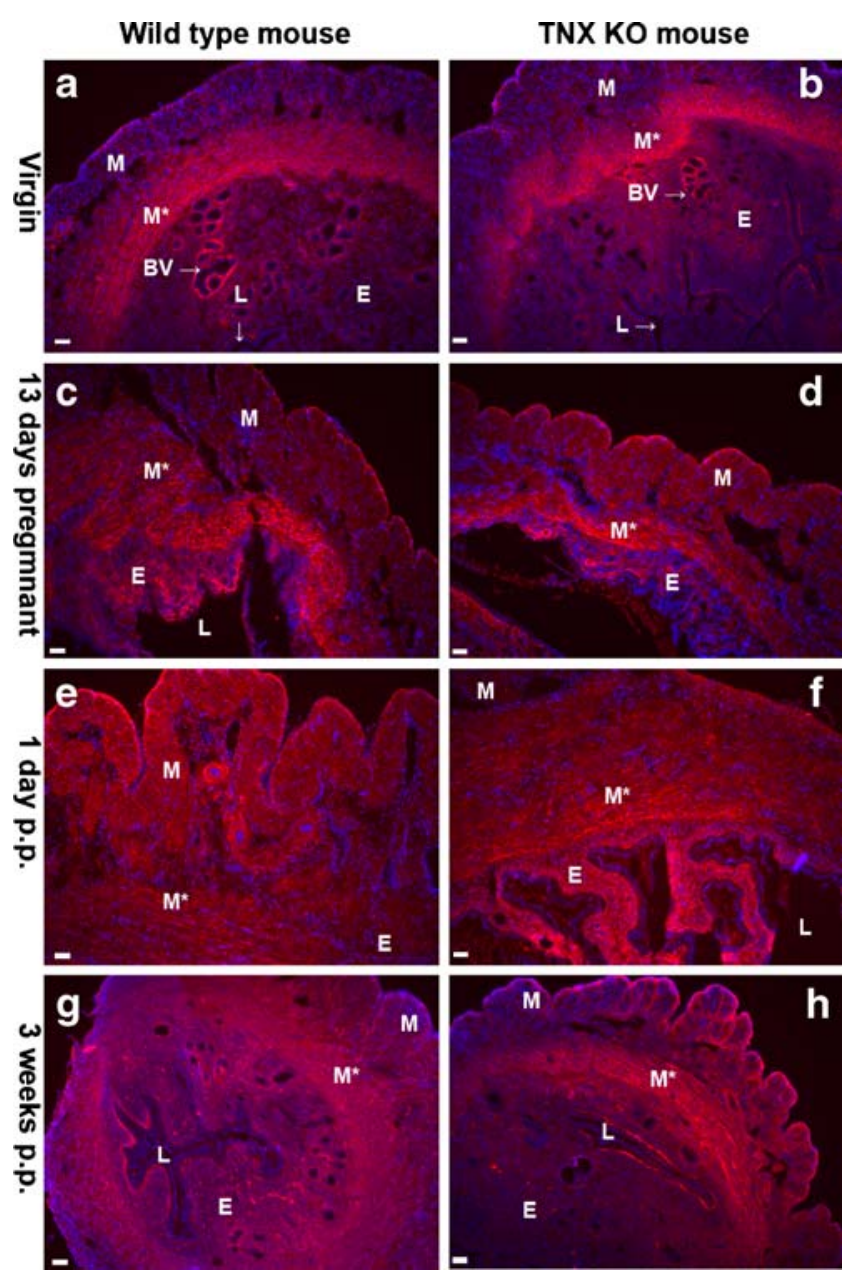

Fig. 5 Immunostaining of collagen type XII in uterus $(P$ perimetrium, $M$ myometrium with longitudinal muscle bundles, $E$ endometrium). Collagen XII (red) is present throughout the uterus. Immunostaining appears to be the strongest in the transverse muscle bundles of the myometrium $\left(M^{*}\right)$, around blood vessels $(B V)$, and around the lumen $(L)$, although the signal intensity is not always completely continuous. No differences in the collagen type XII localization in the uterus between WT (a, c, e, g) and TNX KO $(\mathbf{b}, \mathbf{d}, \mathbf{f}, \mathbf{h})$ mice are observed. Bars $50 \mu \mathrm{m}$

thus we have investigated their structure in TNX KO mouse tissues. Elastic fibers in the uterus are mostly located in the myometrium and perimetrium (Fig. 6a,b). The endometrium contains few elastic fibers as shown for WT (Fig. 6a) and TNX KO (Fig. 6b) mice. In the myometrium and perimetrium, positive staining for elastin is seen predominantly in the layers of connective tissue ensheathing the transverse muscle bundles (Fig. 6c,d). Despite the relative low abundance of mature elastic fibers in the endometrium, the presence of elastin can be detected by immunohistochemistry, possibly a consequence of the sensitivity of the detection methods (Fig. 6c-d). Elastin localization is similar for WT (Fig. 6c) and TNX KO (Fig. 6d) mice. We have previously demonstrated binding of TNX with elastin and the colocalization of these two proteins in skin (Egging et al. 2006a, b). Consistent with these findings, elastin also (partially) colocalizes with TNX in the uterus, as shown in the myometrium (Fig. 6e). Colocalization of TNX with elastin is not complete, since TNX also colocalizes with fibrillar collagens; however, all elastin-reactive material colocalizes with TNX. In previous work, we have showed an increase in elastin-positive material in the skin of aging TNX KO mice (Egging et al. 2006a, b). Although, by light microscopy, the elastic fibers in the TNX KO mouse skin do not appear to be abnormally shaped, an increase in staining might have resulted from an increase in less mature or less organized elastin fibers, an increase in soluble tropoelastin within the matrix, and/or the consequence of more immunoreactive epitopes being available because of an increased susceptibility for degradation. These results are consistent with our past observations of elastic fibers in the skin of TNX-deficient patients in whom irregular and immature elastic fibers and fibers devoid of microfibrils can be seen at the ultrastructural level (Egging et al. 2006b; Zweers et al. 2004). Thus, to expand these findings further in skin and to investigate the elastic fibers in the uterus, we have performed an ultrastructural analysis of the elastic fibers in several tissues. Elastic fibers in WT (Fig. 7a) and TNX KO mice (Fig. 7b) uteri do not appear to differ in shape or size (shown for uterus 3 weeks postpartum). Similarly, in aorta, the elastic laminae of WT (Fig. 7c) and TNX KO mice (Fig. 7d) are similar in shape and number (aorta of 9-month-old mice). In skin of older TNX KO mice (as shown for 9-month-old mice), however, a difference in elastic fiber ultrastructure is apparent compared with WT skin. In addition to normal-appearing elastic fibers, irregular elastin aggregates, as seen in the skin of TNX-deficient patients (Zweers et al. 2004), can be observed (Fig. 7e,f). These elastin aggregates are not found in the skin of 2-month-old TNX KO mice or in 9-month-old WT mice. Interestingly, elastic fibers in the skin of 9-month-old TNX KO mice often appear larger than those of WT mice of the same age (compare Fig. 7g,h).

\section{Discussion}

GU complications occur frequently in patients with various types of EDS (Carley and Schaffer 2000; Ramos-e-Silva et al. 2006; Lind and Wallenburg 2002; Kuczkowski 2005; Parry and Strauss 1998; Pepin et al. 2000). In classical and hypermobility types of EDS, which are the most common, the outcome of pregnancy is generally favorable. Maternal complications however, such as postpartum hemorrhage and pelvic instability, are more common than in the general population (Ramos-e-Silva et al. 2006; Kuczkowski 2005; Parry and Strauss 1998). Furthermore, EDS patients appear to have an elevated risk of uterine prolapse (Carley and Schaffer 2000; Lind and Wallenburg 2002). Pregnancy in 


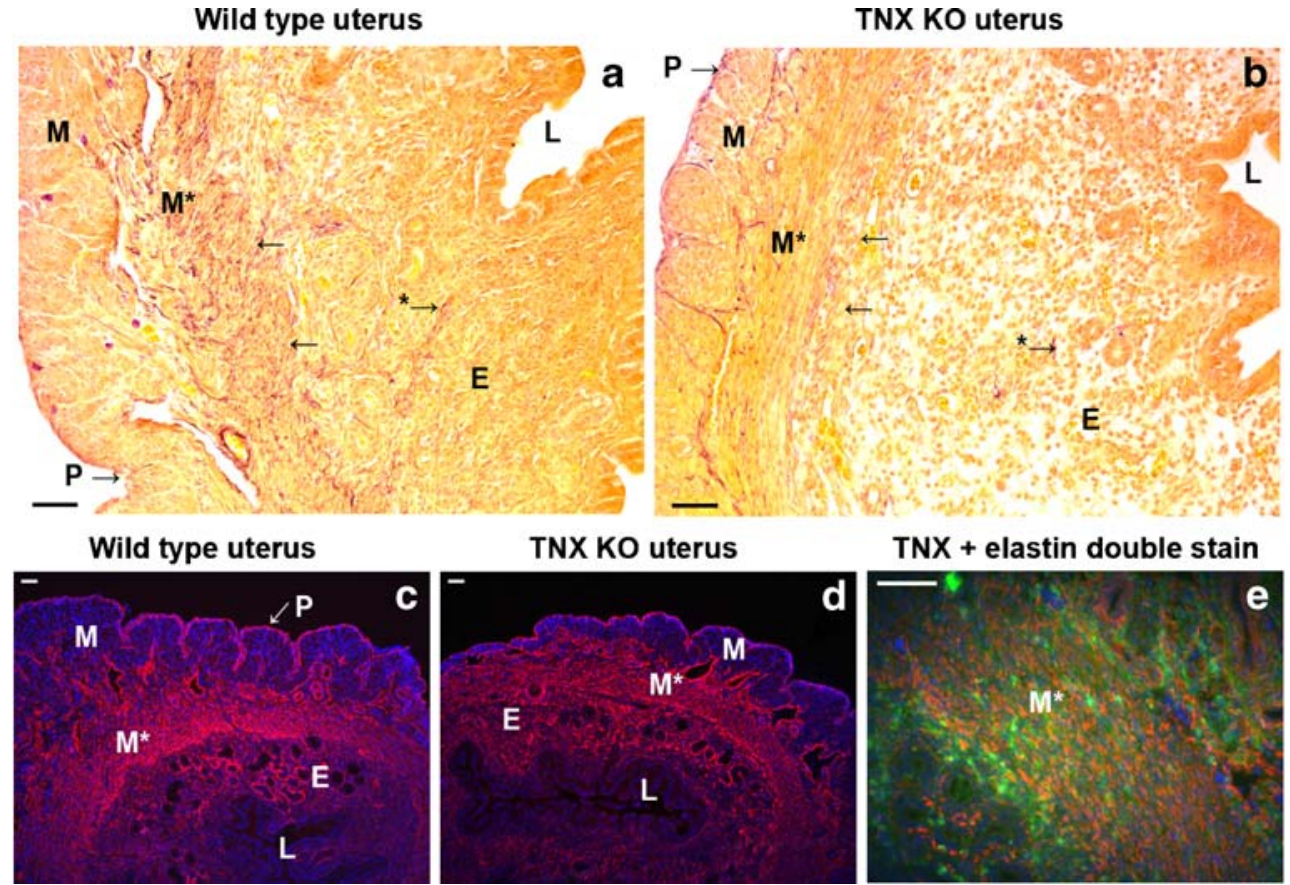

Fig. 6 Elastin and elastic fibers in the uterus ( $L$ lumen). Elastic fibers (purple, modified Hart's staining) are mostly located in the myometrium $\left(M, M^{*}\right)$ and perimetrium $(P)$, whereas the endometrium $(E)$ appears to contain fewer elastic fibers in WT (a) and TNX KO (b) mice. No elastic fiber abnormalities are found in the TNX KO mice. Elastin immunostaining (red) is observed in the myometrium, predominantly in the transverse bundles $\left(M^{*}\right.$ in $\left.\mathbf{c}, \mathbf{d}\right)$. The layers of connective tissue ensheathing the muscle bundles of the myometrium $(M)$ and perimetrium $(P)$ are stained positively for elastin (red). Strong elastin staining is also seen in the endometrium $(E)$. Elastin immunoreactivity is similar for WT (c) and TNX KO (d) mice. Elastin (red) colocalizes (orange) with TNX (green) in the myometrium $\left(M^{*}\right.$ in e). Not all TNX colocalizes with elastin as TNX also colocalizes with different collagen types (Fig. 4). Bars $50 \mu \mathrm{m}$ patients with vascular type EDS may even lead to maternal death through uterus or vessel rupture (Pepin et al. 2000). We have investigated pregnancies and GU abnormalities in TNX-deficient woman of reproductive age. Generally, pregnancy is without major complications in TNX-deficient patients, apart from one noted incident of postpartum hemorrhage. However, uterine and vaginal prolapse regularly occur in TNX-deficient women, even at a young age, suggesting laxity of GU tissues. Premature rupture of fetal membranes is a risk in pregnancy with EDS affected fetuses (Lind and Wallenburg 2002; Parry and Strauss 1998). No premature births have been observed in the offspring of the TNX-deficient patients; however, some TNX-deficient patients had been born prematurely. Obviously, some caution must be taken in making conclusions and extrapolating data from such a small group of TNX-deficient woman.

Complete TNX deficiency in humans is a rare condition, and so far, only a few patients have been identified. We have therefore investigated pregnancy and uterine tissue structure in our TNX KO mouse model. No gross significant differences have been found with regard to abnormalities during pregnancy or reproduction between the TNX KO and WT mice. A trend toward a reduction in the length of pregnancy in TNX KO mice. The only significant difference has been observed in the location of the vaginal plugs, which suggests laxity in the vaginal wall.

In a previous study, we have not found any differences in cutaneous collagen deposition between TNX KO and WT mice (Egging et al. 2006b), as has been observed in the skin of TNX-deficient patients (Schalkwijk et al. 2001; Zweers et al. 2004). Alterations in collagen deposition in the skin of TNX KO mice is, however, a matter of debate (Egging et al. 2006b; Mao et al. 2002; Minamitani et al. 2004). In the present study, we have found elastin aggregates and enlarged elastic fibers in 9-month-old skin of TNX KO mice at the ultrastructural level; this is in accordance with our previously published data concerning increased elastin staining in aging TNX KO mouse skin (Egging et al. 2006b). We have detected no differences in elastic fibers in the uterus or elastic laminae of the abdominal aorta between TNX KO and WT mice suggesting a specific role for TNX in the maturation or maintenance of elastic fibers in skin. However, abnormal elastic fibers might not be present in the uterus, since the ECM is constantly being remodeled during the menstrual cycle and pregnancy.

Although the TNX KO mice appear to have a much milder phenotype compared with TNX-deficient humans, the skin of TNX KO mice is significantly weaker and more lax compared with WT mice (Bristow et al. 2005; Burch 
Fig. 7 Ultrastructural evaluation of elastic fibers. Elastic fibers in WT (a) and TNX KO (b) mouse uterus do not appear to differ in shape or size. The dark structures (arrows) are elastic fibers (shown for uterus at 3 weeks postpartum). The elastic laminae (arrows) in the aorta of WT (c) and TNX KO (d) mice are similar in shape and number (aorta of 9-month-old mice). Skin of older TNX KO mice ( 9 months old) shows differences in elastic fibers from those of WT skin. Irregular elastin aggregates can be observed in the TNX KO mouse skin (e, near a sebaceous gland). A higher magnification of an elastin aggregate (arrow) is shown in $\mathbf{f}$. These aggregates were not found in skin of 2month-old TNX KO mice or in 9-month-old WT mice. No irregularities in the shape of elastic fibers are observed in 9month-old TNX KO mice skin; however, larger elastic fibers than in WT mice (g) are often observed in the TNX KO mice (h, arrows elastic fibers). Bars $0.5 \mu \mathrm{m}(\mathbf{a}, \mathbf{b}), 10 \mu \mathrm{m}(\mathbf{c}, \mathbf{d})$, $2 \mu \mathrm{m}(\mathbf{e}, \mathbf{g}, \mathbf{h}), 1 \mu \mathrm{m}(\mathbf{f})$
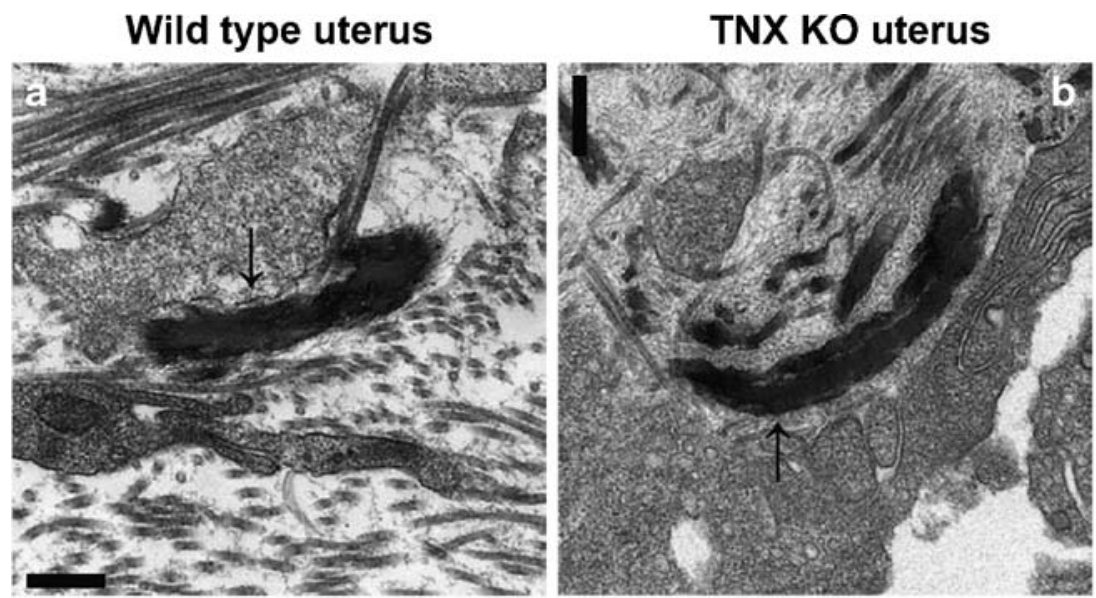

WT aorta

TNX KO aorta

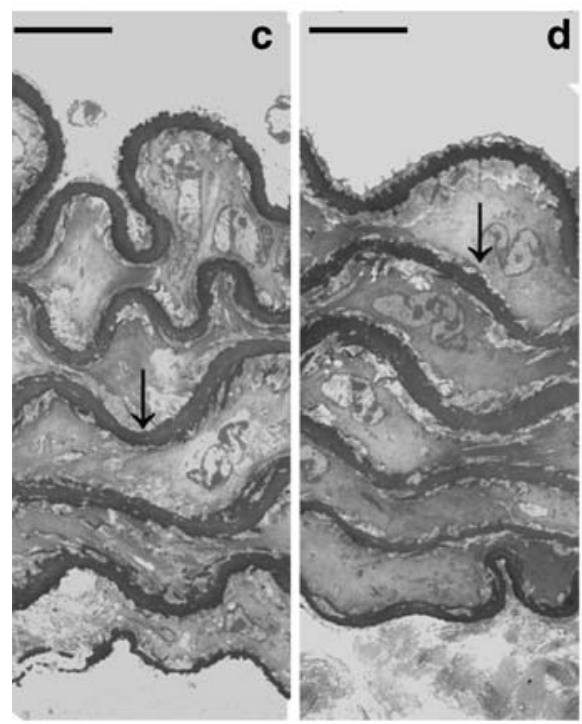

Wild type skin (9 month)

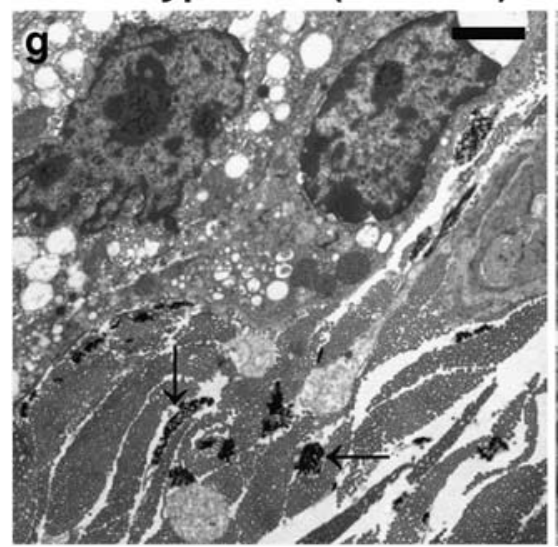

TNX KO skin

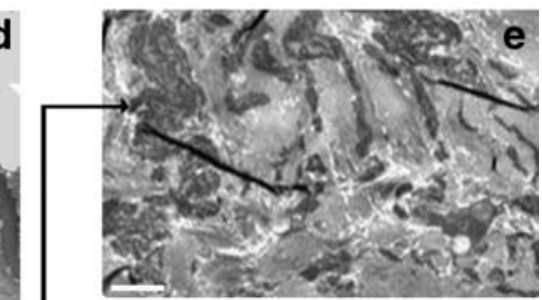

TNX KO skin

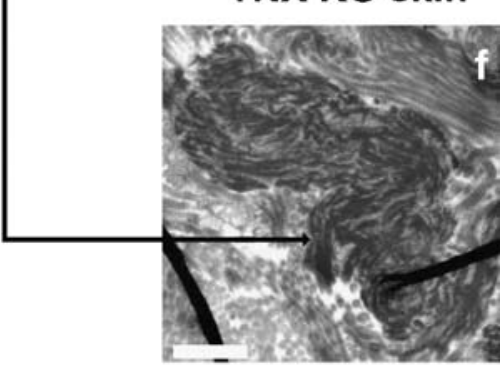

TNX KO skin (9 month)

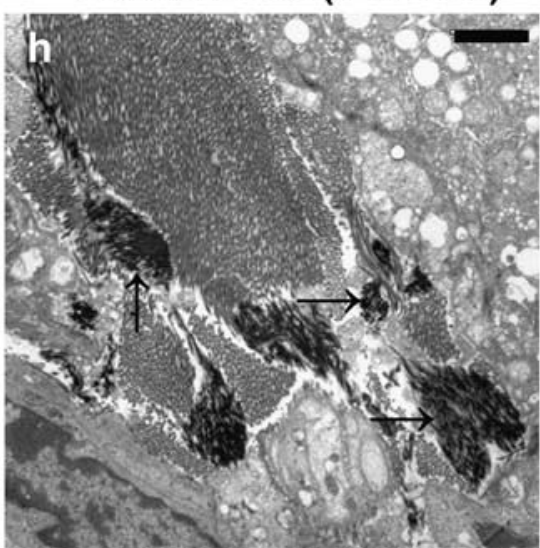

et al. 1997; Egging et al. 2006b; Lindor and Bristow 2005; Mao et al. 2002; Matsumoto et al. 2001; Minamitani et al. 2004; Schalkwijk et al. 2001; Zweers et al. 2004). Our data suggest a more lax vaginal canal in TNX-deficient patients and to a certain degree in TNX KO mice. An attractive speculation, considering the observations from our studies in mice, is that TNX is essential for tissue integrity, independent of the quantity of collagen deposition or elastic fiber structure. In conclusion, we would advise obstetricians and gynecologists to monitor TNX-deficient patients closely, as they are likely to have weaker GU connective tissue and could therefore be at risk of GU complications. 
Acknowledgements We are grateful to Ilona van den Brink, Geert Poelen, Debby Smits, and Brenda van Vliet of the Central Animal laboratory of the Radboud University Nijmegen for their technical assistance. Willeke Blokx of the Department of Pathology of the UMC Nijmegen, is acknowledged for the histopathological evaluation of mouse uteri. Jim Bristow of the Lawrence Berkeley National Laboratory, USA, is acknowledged for providing the original TNX KO mice and discussion.

Open Access This article is distributed under the terms of the Creative Commons Attribution Noncommercial License which permits any noncommercial use, distribution, and reproduction in any medium, provided the original author(s) and source are credited.

\section{References}

Ainsworth SR, Aulicino PL (1993) A survey of patients with EhlersDanlos syndrome. Clin Orthop Relat Res 286:250-256

Beighton P, De Paepe A, Steinmann B, Tsipouras P, Wenstrup RJ (1998) Ehlers-Danlos syndromes: revised nosology, Villefranche, 1997. Ehlers-Danlos National Foundation (USA) and EhlersDanlos Support Group (UK). Am J Med Genet 77:31-37

Bristow J, Carey W, Egging D, Schalkwijk J (2005) Tenascin-X, collagen, elastin, and the Ehlers-Danlos syndrome. Am J Med Genet C Semin Med Genet 139:24-30

Bristow J, Tee MK, Gitelman SE, Mellon SH, Miller WL (1993) Tenascin-X: a novel extracellular matrix protein encoded by the human XB gene overlapping P450c21B. J Cell Biol 122:265-278

Burch GH, Gong Y, Liu W, Dettman RW, Curry CJ, Smith L, Miller WL, Bristow J (1997) Tenascin-X deficiency is associated with Ehlers-Danlos syndrome. Nat Genet 17:104-108

Carley ME, Schaffer J (2000) Urinary incontinence and pelvic organ prolapse in women with Marfan or Ehlers Danlos syndrome. Am J Obstet Gynecol 182:1021-1023

Davis EC (1993) Smooth muscle cell to elastic lamina connections in developing mouse aorta. Role in aortic medial organization. Lab Invest 68:89-99

Egging D, Berkmortel F van den, Taylor G, Bristow J, Schalkwijk J (2006a) Interactions of human tenascin-X domains with dermal extracellular matrix molecules. Arch Dermatol Res 298:389-396

Egging DF, Vlijmen I van, Starcher B, Gijsen Y, Zweers MC, Blankevoort L, Bristow J, Schalkwijk J (2006b) Dermal connective tissue development in mice: an essential role for tenascin-X. Cell Tissue Res 323:465-474

Egging D, Vlijmen-Willems I van, Tongeren T van, Schalkwijk J, Peeters A (2007) Wound healing in tenascin-X deficient mice suggests that tenascin- $X$ is involved in matrix maturation rather than matrix deposition. Connect Tissue Res 48:93-98

Elefteriou F, Exposito JY, Garrone R, Lethias C (1997) Characterization of the bovine tenascin-X. J Biol Chem 272:22866-22874

Ikuta T, Sogawa N, Ariga H, Ikemura T, Matsumoto K (1998) Structural analysis of mouse tenascin-X: evolutionary aspects of reduplication of FNIII repeats in the tenascin gene family. Gene 217:1-13

Kuczkowski KM (2005) Ehlers-Danlos syndrome in the parturient: an uncommon disorder-common dilemma in the delivery room. Arch Gynecol Obstet 273:60-62

Lethias C, Descollonges Y, Boutillon MM, Garrone R (1996) Flexilin: a new extracellular matrix glycoprotein localized on collagen fibrils. Matrix Biol 15:11-19
Lind J, Wallenburg HC (2002) Pregnancy and the Ehlers-Danlos syndrome: a retrospective study in a Dutch population. Acta Obstet Gynecol Scand 81:293-300

Lindor NM, Bristow J (2005) Tenascin-X deficiency in autosomal recessive Ehlers-Danlos syndrome. Am J Med Genet A 135:75-80

Mao JR, Taylor G, Dean WB, Wagner DR, Afzal V, Lotz JC, Rubin EM, Bristow J (2002) Tenascin-X deficiency mimics EhlersDanlos syndrome in mice through alteration of collagen deposition. Nat Genet 30:421-425

Matsumoto K, Takayama N, Ohnishi J, Ohnishi E, Shirayoshi Y, Nakatsuji N, Ariga H (2001) Tumour invasion and metastasis are promoted in mice deficient in tenascin-X. Genes Cells 6:1101-1111

Minamitani T, Ikuta T, Saito Y, Takebe G, Sato M, Sawa H, Nishimura T, Nakamura F, Takahashi K, Ariga H, Matsumoto K (2004) Modulation of collagen fibrillogenesis by tenascin-X and type VI collagen. Exp Cell Res 298:305-315

Morel Y, Bristow J, Gitelman SE, Miller WL (1989) Transcript encoded on the opposite strand of the human steroid 21hydroxylase/complement component $\mathrm{C} 4$ gene locus. Proc Natl Acad Sci USA 86:6582-6586

Parry S, Strauss JF III (1998) Premature rupture of the fetal membranes. N Engl J Med 338:663-670

Peeters ACTM, Kucharekova M, Timmermans J, Berkmortel FWPJ van den, Boers GH, Novakova IRO, Egging D, Heijer M den, Schalkwijk J (2004) A clinical and cardiovascular survey of Ehlers-Danlos syndrome patients with complete deficiency of tenascin-X. Neth J Med 62:23-25

Pepin M, Schwarze U, Superti-Furga A, Byers PH (2000) Clinical and genetic features of Ehlers-Danlos syndrome type IV, the vascular type. N Engl J Med 342:673-680

Ramos-e-Silva M, Libia Cardozo PA, Bastos OG, Coelho da Silva CS (2006) Connective tissue diseases: pseudoxanthoma elasticum, anetoderma, and Ehlers-Danlos syndrome in pregnancy. Clin Dermatol 24:91-96

Roop KA, Brost BC (1999) Abnormal presentation in labor and fetal growth of affected infants with type III Ehlers-Danlos syndrome. Am J Obstet Gynecol 181:752-753

Schalkwijk J, Zweers MC, Steijlen PM, Dean WB, Taylor G, Van Vlijmen IM, Haren B van, Miller WL, Bristow J (2001) A recessive form of the Ehlers-Danlos syndrome caused by tenascin-X deficiency. N Engl J Med 345:1167-1175

Starcher B, Aycock RL, Hill CH (2005) Multiple roles for elastic fibers in the skin. J Histochem Cytochem 53:431-443

Tucker RP, Drabikowski K, Hess JF, Ferralli J, Chiquet-Ehrismann R, Adams JC (2006) Phylogenetic analysis of the tenascin gene family: evidence of origin early in the chordate lineage. BMC Evol Biol 6:60

Veit G, Hansen U, Keene DR, Bruckner P, Chiquet-Ehrismann R, Chiquet M, Koch M (2006) Collagen XII interacts with avian tenascin-X through its NC3 domain. J Biol Chem 281:27461-27470

Wegrowski Y, Bellon G, Quereux C, Maquart FX (1999) Biochemical alterations of uterine leiomyoma extracellular matrix in type IV Ehlers-Danlos syndrome. Am J Obstet Gynecol 180:1032-1034

Zweers MC, Bristow J, Steijlen PM, Dean WB, Hamel BC, Otero M, Kucharekova M, Boezeman JB, Schalkwijk J (2003) Haploinsufficiency of TNXB is associated with hypermobility type of Ehlers-Danlos syndrome. Am J Hum Genet 73:214-217

Zweers MC, Vlijmen-Willems IM, Van Kuppevelt TH, Mecham RP, Steijlen PM, Bristow J, Schalkwijk J (2004) Deficiency of tenascin-X causes abnormalities in dermal elastic fiber morphology. J Invest Dermatol 122:885-891 